\title{
Editorial on ICT: From E-readers and computer games to basketball
}

\author{
Arthur Tatnall
}

Published online: 15 June 2013

(C) Springer Science+Business Media New York 2013

The third issue of EAIT for 2013 contains 8 articles covering a range of topics relating to ICT and Education. Firstly there is an article by Maria Rasmusson and Monica Eklund from Sweden: It's easier to read on the Internet-you just click on what you want to read... In the article the authors note that today's youth spend a lot of time on the Internet, and that on-line reading is thus an issue worth investigating. Their study explores reading on the Internet, with pairs of Swedish students aged 10 and 15. The study found that five main categories of skills and abilities were relevant: traditional literacy, multimodal literacy, path-finding, IT abilities, and information abilities. The article also highlights the crucial need for the ability of students to be able to spell and to know web address conventions in English.

Next follows an article by Marcy Zipke from the USA titled: Teachers' thoughts on e-readers in the elementary school classroom. The article investigates advantages and disadvantages to teaching elementary literacy with e-readers, using a convenience sample of ten e-reader novice teachers equipped with Kindle e-readers. The article discusses issues with implications related to pedagogy including the text-to-speech and dictionary functions and the idea of unlimited access to books.

Individual and group performance of computerized educational tasks is an article by Joseph Klein from Israel. His study examines the conditions under which task performance is accomplished more efficiently by a single individual or by a group. The study involved use of a computer game based on educational software and arranged in five levels of difficulty. A comparison was made of the speed in which objectives were attained when performed individually compared to when divided among groups of two to four partners.

Marina Papastergiou and Vassilis Gerodimos from Greece discuss basketball and ICT in an article titled: Can learning of basketball be enhanced through a web-based multimedia course? An experimental study. This study aimed to create a web-based multimedia course for Physical Education students to familiarise them with the

\footnotetext{
A. Tatnall $(\bowtie)$

Victoria University, PO Box 14428, Melbourne 8001, Australia

e-mail: Arthur.Tatnall@vu.edu.au
} 
teaching of basketball. It also aimed to evaluate its use as a complementary tool to conventional instruction, in terms of learning effectiveness and student acceptance.

A review of empirical research on blended learning in teacher education programs is described by Jared Keengwe and Jung-Jin Kang from the USA. The authors note that blended learning has been considered as an important alternative approach that can overcome various limitations related to both face-to-face and online learning, and provide a review of empirical research studies on teacher education programs using activity theory. They hope that this will stimulate reflections on effective strategies for design and implementation of blended learning teacher education programs.

The next article: Why teachers use digital learning materials: The role of selfefficacy, subjective norm and attitude is by Frederik Van Acker, Hans van Buuren, Karel Kreijns and Marjan Vermeulen from the Netherlands. In the article they note that although ICT seems a promising tool in an educational context, many teachers are reluctant to integrate it in their daily practice. Basing on the Integrative Model of Behaviour Prediction it was conjectured that self-efficacy, attitude and subjective norm would take a central role in explaining the intention to use digital learning materials. The study outcomes suggest that persuasive communication focusing on positive outcomes and skills based training seem appropriate interventions to promote a positive attitude and improve self-efficacy in using digital learning materials.

Technology and education: ICT in Ugandan secondary schools by Landon S. Newby from the UK, Julie M. Hite and Steven J. Hite from the USA and Christopher B. Mugimu from Uganda follows. The article argues that if adopted and implemented appropriately ICTs could support learning and teaching in developing countries to provide young people with skills they need to participate effectively in the global economy. This study examines ICT infrastructure and use in 11 secondary schools in Mukono, Uganda using qualitative case study methods including an ICT infrastructure assessment, observations, and interviews.

The final article in this issue: Design and evaluation of a computer game for the learning of Information and Communication Technologies (ICT) concepts by physical education and sport science students by Rosana Margarida Couceiro from Portugal and Marina Papastergiou, Maria Kordaki and Ana Isabel Veloso from Greece addresses the learning of ICT concepts by physical education and sport science students through a computer game. The study investigated designing the prototype of a game to support development by students of an appropriate mental model about how a computer works, and the evaluation of the impact of the use of this on students as to appeal, basic usability issues and learning outcomes.

Again, articles in this issue contain a range of topics from countries around the world. What I would particularly like to see in future issues however, is articles that discussed national policy issues, how these have developed and what effect they have had. Issues relating to the use of ICT with minority groups and developing countries would also be very welcome. The waiting time for publication for an article in EAIT is now about 12-15 months after acceptance, but because of their importance, articles of these types will be given preference.

\section{Arthur Tatnall}

Editor-in-Chief 